\title{
PSYCHOLOGICAL FACTORS OF MALADJUSTED TEENAGERS
}

\author{
Yusufaliev Elyorjon Mashrabovich \\ Head of the Department of English Language and Literature, Kokand State Pedagogical Institute
}

Article DOI: $\underline{\text { https://doi.org/10.36713/epra3743 }}$

ABSTRACT

The overwhelming majority of adolescent delinquency has purely social causes, disadvantages of upbringing above all. From 30 to $85 \%$ of delinquent adolescents grow up in an incomplete family, that is, without a father, or in a family deformed - with a recently appeared stepfather, less often, with a stepmother.

KEY WORDS: teenagers, psychological factors, social upheaval, deviant, emotional and psychological relations, criminalizing factor, biopsychological aspects.

\section{INTRODUCTION}

The overwhelming majority of adolescent delinquency has purely social causes, disadvantages of upbringing above all. From 30 to $85 \%$ of delinquent adolescents grow up in an incomplete family, that is, without a father, or in a family deformed - with a recently appeared stepfather, less often, with a stepmother.

\section{METHODOLOGY}

The study was conducted using objectivity, analysis, synthesis, comparative analysis, generalization, historical analysis, chronological methods.

\section{RESULTS}

The growth of delinquency among adolescents is accompanied by social upheaval, entailing fatherlessness and depriving of family custody[1]. Delinquency is far from always associated with character anomalies, with psychopathologies. Moreover, for some of these anomalies, including extreme variants of the norm in the form of accentuations of character, there is less stability with respect to the adverse effects of the immediate environment, and greater compliance with harmful influences. The emergence of socially unapproved forms of behavior speak of a condition called social maladaptation. No matter how diverse these forms are, they are almost always characterized by poor relationships with other children, which are manifested in fights, quarrels, or, for example, aggressiveness, demonstrative disobedience, destructive actions or deceit. They may also include antisocial acts such as theft, absenteeism and arson. There are important connections between these various forms of behavior. They are manifested in the fact that those children who were aggressive and cocky at an early school age, becoming older, are more likely to become prone to antisocial behavior. Social maladaptation syndrome is much more common among boys. What is clearly manifested in cases of antisocial acts. Adolescents with the so-called socialized forms of antisocial behavior are not characterized by emotional disorders and, moreover, they easily adapt to social norms within those antisocial groups of friends than relatives to whom they belong. Such children often come from large families, where inappropriate upbringing measures are applied and where antisocial forms of behavior are learned from the immediate family environment.

All forms of diverting behavior naturally lead to a violation of legislative norms. Going beyond social rules, accompanied by extraordinary cruelty, is always 


\section{SJIF Impact Factor: 7.001| ISI I.F.Value:1.241| Journal DOI: 10.36713/epra2016 EPRA International Journal of Research and Development (IJRD)}

suspicious as a possible mental anomaly. Deviant and delinquent forms of behavior is an adaptation to the social and psychological realities of adolescence and youth, although it is condemned by society for its extremism. Many of the causes of the violation of adolescent behavior can be identified and addressed in a timely manner. At the same time, among the factors of deviant behavior, those are found for the prevention and elimination of which no effective means have yet been found. Psychological and pedagogical factors can be fully attributed to this category. So, more and more often, when determining the causes and conditions of violation by teenagers of norms and rules of behavior, we turn to an analysis of the psychological climate of the family, the emotional and psychological relations of a teenager with peers and adults. Deviating behavior is often explained by the fact that a child, teenager or youth cannot by lawful means satisfy their sociopsychological needs for recognition, trust, selfaffirmation. A significant part of discipline violations is committed by adolescents in a state of reduced level of psychological activity or in a state bordering between norm and pathology. Therefore, the prevention and overcoming of difficulties in the education of students of adolescents depends on the correctness and completeness of the determination of the factors that generate and cause deviation. Russian psychologists and many modern foreign scientists deny the decisive influence on the behavior of "difficult" children of the genetic factor, the hereditary burden of their consciousness and actions. Natural prerequisites for certain features of the psyche, of course, exist. Undergoing qualitative changes, they do not act directly, but through special factors. The formation of criminal trends by most authors is considered to be a process of interaction of biological and social causes. Social influence (intra-family conflicts, the impact of the example of adolescent groups, the information climate, the prevalence of certain values in society, etc.) acts as a pathogenic external factor that affects all adolescents without exception, and either a catalyst of antisocial and anti-moral ideas, or a factor in reducing the compensatory capabilities of the individual in its opposition to alien influence[2]. The main causes of adolescent difficulties: in the wrong relationships in the family, in school miscalculations, isolation from peers, in general maladaptation, in the desire to establish oneself in any way and in any small group. Often there is a combination, a complex of all these reasons. Violations of the behavior and emotional-volitional sphere of children, adolescents, youth are not inherited. Exceptions are associated with a rare number of diseases caused by mental retardation. Another reason for deviations is the age-related features of the psyche of a teenager. Mental development is characterized by age-related crises. With their educational influences of adults, the appearance of a child begins to resist the educational influences of adults, conflict with them, rude and disobedient to behave. L.S. Vygotsky spoke of crises of a newborn, 1 year old, 3,7,13 and 17 years old. The period of adulthood, in itself, is not a disease, but can provoke the emergence of deep psychological problems. A teenage crisis is understood as a condition in which "distortions of a teenager's relationship with reality" may occur (H.Remschmidt., 1992). One of the cardinal signs of this crisis is the experience of alienation of one's self (depersonalization), one's loneliness and isolation from the world. Many aggressive actions of adolescents that fall into the field of view of law enforcement agencies are a consequence of a personality crisis. [3] Particularly worth mentioning are the complications of adolescence that entail the rapid and uneven development of the body that accompanies the process of puberty in a teenager. This unevenness can manifest itself both in the development of the musculoskeletal system and somatic body organization, and in the development of the cardiovascular system and internal organs of a teenager. In one case, this leads to somatic imbalances (high growth with a small head, narrow chest, long limbs, etc.), which is painfully perceived by a teenager. In another case, the uneven development of the cardiovascular system can lead to blood pressure, headaches. And, perhaps, the increased activity of the endocrine system, the so-called "hormonal storm" caused by accelerated puberty, and, as a result of this, emotional instability, increased excitability, imbalance, inadequacy of the reaction, resulting in unjustified sharpness and increased ability, can exert the most noticeable behavior on a teenager conflict, which in itself can complicate his relationship with others. The increased conflict, especially in relation to adults, which often manifests itself in adolescence, is explained not only by organic changes, but also by the body, which changes the whole system of relations between a teenager and adults, and with peers. In an effort to get rid of the assessment and influence of adults, a teenager becomes critical of his parents and teachers, begins to sharply feel and notice their shortcomings. The active process of mastering social behavior skills continues. The crisis of adolescence with a more or less pronounced tendency to criminalization is also manifested in the fact that a teenager has significantly restructured relationships with peers. A teenager is characterized by an increased need for communication with peers, a desire for selfaffirmation in their midst, and a sensitive reaction to the opinion of peers. Such manifestations at this age are by no means accidental. They are due to the fact that in adolescence, self-consciousness, self-esteem are laid. The need for communication and self-affirmation of a teenager should be realized in a favorable environment. 


\section{SJIF Impact Factor: 7.001| ISI I.F.Value:1.241| Journal DOI: 10.36713/epra2016 EPRA International Journal of Research and Development (IJRD)}

If for some reason this does not happen, selfaffirmation is carried out in informal teenage groups, street, yard companies in the form of asocial manifestations (drinking, smoking, obscene language, hooliganism), it can become a dangerous, criminalizing factor. [4] Teenage grouping reactions are closely related to the crisis processes of self-awareness. Antisocial companies (socially negative) are associated with entertainment and communication, but they are based on activities aimed at harming society. The origins of gang crime lie in the neglect of street companies whose leaders are difficult teenagers or adult offenders. A healthy youthful craving for collectivity is expressed here as a dangerous group egoism, uncritical hyperidentification with a group and its leader, inability and unwillingness to consciously weigh and evaluate private group norms and values in the light of more general social and moral criteria. Obeying the laws of the group, adolescents go to incredibly violent crimes in order to, as it seems to them, "restore the vital connection of their own Self with the group"[5]. Amorphous morality of a teenager makes him dependent in his judgments on the opinions of others. Compensation for non-independence, for all this, is achieved through extreme devotion to the commonality of "we" and a critical, nihilistic attitude towards all who are included in "them." "Difficult" adolescents have a strongly developed "imitation reflex", which encourages them not to critically adopt behaviors from more advanced adolescents. This explains the increase in the degree of difficulty in education, regardless of the pedagogical influences of movements along the vector of deviant behavior, up to delinquency (offense). With the anatomical and physiological transformations of the body in a teenager, one can observe an increase in interest in the topic of "sexual norm". Moreover, the results of "measuring" the standards of adult sexual behavior are mostly not in his favor, which causes either various manifestations of sexual aggression or anxiety. Distorted development of sexual interest, orientation to various kinds of ersatz of sexual relations lead individual adolescents to sexual perversions of immoral acts, individual and group offenses. Adolescents, as a rule, avoid talking with adults about biopsychological aspects of the relationship between men and women, hide their awareness or, on the contrary, show shamelessness, open cynicism when they want to shock others and prove their maturity[6]. Quickly and easily, teenagers master the "forbidden" methods of psychological defense against attack, which are found in the arsenal of an adult: crowding out unpleasant ideas about the consequences of their act, cunning, deceit, conformity to compliance with a demand, demonstration of physical strength, aggressiveness, rudeness, threat, blackmail. A separate group is constituted by factors of difficult education connected with the negative impact on the pedagogical process of the dysfunctional family of a teenager. The family, in this case, should be considered primarily as a factor determining the psychophysiological usefulness or inferiority of the child. A dysfunctional family can have a direct decomposing effect on a formative personality and impede its normal development. Negative family conditions, the absence of a normal, moral environment, the violation of psychological contact with the closest people are acutely experienced by adolescents who begin to recognize the contradiction of adult life. Bitterness, leading to despair or cruelty, distrust of people, disregard for norms, cynicism, indifference - this is not a complete list of the inner attitudes of a teenager who are experiencing disagreement or divorce of parents living in conditions of drunkenness, debauchery, incessant quarrels and conflicts, ignorance, indifference . Moreover, there are frequent cases when a distorted moral atmosphere around a child is created by those who love him and wish him all the best. Great harm by their actions is done by parents who try to preempt all his desires, impose their ideas about the world, lifestyle criteria among people. "The artificial delay of childhood is fraught with dangerous consequences," writes I.S. Con - Young people who do not take a serious part in social activities do not develop a sense of responsibility inherent in an adult. Their activity can be directed through antisocial channels, resulting in drunkenness, hooliganism, all kinds of crime. A special place among the unfavorable individual characteristics that make up the psychophysiological prerequisites for antisocial behavior is occupied by a lag in mental development, oligophrenia, and congenital craniocerebral injuries. In some cases, the role of prerequisites may be various physical defects, speech defects, external unattractiveness, constitutional-somatic deficiencies. Thus, adolescence is a difficult period of mental development; it is difficult for the teenager himself, he is difficult when working with him. A tangle of internal contradictions of this age, especially acute at this stage, the resistance of adolescents to education lead to the emergence of a large group of difficult adolescents. Antisocial behavior is interdependent on the influence of factors, primarily, the external social environment (especially the microenvironment), as well as the individual personality traits of the adolescent, which determine his individual response to various "life failures".

\section{CONCLUSION}

The causes leading to psychological disorders, character accentuations are associated both with organic brain injuries (birth asphyxia, traumatic brain injuries, severe intoxication) and social factors, in 
which the conditions for family education can be put in the first place. Most often, these factors are so closely related that they cause serious difficulties for researchers in determining the root cause of "deviant" behavior in adolescents.

\section{LITERATURE}

1. Mendelevich V.D. Psychology of deviant behavior. - M., $2010-488$ p.

2. Zmanovskaya E.V. Deviantology: the psychology of deviant behavior. M., 2003. $-288 p$.

3. Alexandrov A.A. Behavioral deviations in adolescents. - Lviv, 1998. - $197 p$.

4. Lichko A.E. Psychopathies and character accentuations in adolescent offenders. - M., 1998. $130 \mathrm{~s}$.

5. Kudryavtsev V.N. The struggle of motives in criminal behavior. - M., 2007. $-52 p$.

6. Gilinsky $Y$. V. Deviance of adolescents: theory, methodology, empirical reality. - SPb., 2012. $200 \mathrm{p}$. 